\title{
Mutation screening in 18 Caucasian families suggest the existence of other MODY genes
} \author{
G. Charpentier ${ }^{6}$, D. Beckers ${ }^{7}$, M. Maes ${ }^{7}$, C. Bellanné-Chantelot ${ }^{2}$, G. Velho $^{8}$, P. Froguel ${ }^{1}$ \\ ${ }^{1}$ Institut de Biologie de Lille, CNRS EP-10, Institut Pasteur, Lille, France \\ ${ }^{2}$ Fondation Jean Dausset - CEPH, Paris, France \\ ${ }^{3}$ CEPEN, Santa Casa Hospital, Belo Horizonte, MG, Brazil \\ ${ }^{4}$ Service d'Immunologie Clinique, Hôpital Necker-Enfants Malades, Paris, France \\ ${ }^{5}$ Service de Diabétologie, Hôpital Bichat, Paris, France \\ ${ }^{6}$ Service d'Endocrinologie, Hôpital Gilles de Corbeil, Corbeil-Essonnes, France \\ ${ }^{7}$ Clinique Universitaire Saint-Luc, Bruxelles, Belgium \\ ${ }^{8}$ INSERM U-342, Hôpital Saint Vincent de Paul, Paris, France
}

J.-C. Chèvre ${ }^{1}$, E.H. Hani ${ }^{1}$, P. Boutin ${ }^{1}$, M. Vaxillaire ${ }^{1}$, H. Blanché ${ }^{2}$, N. Vionnet ${ }^{1}$, V. C. Pardini ${ }^{3}$, J. Timsit ${ }^{4}$, E. Larger ${ }^{5}$,

Summary Maturity-onset diabetes of the young (MODY) is a heterogeneous subtype of non-insulindependent diabetes mellitus characterised by early onset, autosomal dominant inheritance and a primary defect in insulin secretion. To date five MODY genes have been identified: hepatocyte nuclear factor- 4 alpha (HNF-4a/MODY1/TCF14) on chromosome $20 \mathrm{q}$, glucokinase (GCK/MODY2) on chromosome $7 \mathrm{p}$, hepatocyte nuclear factor-1 alpha (HNF-1 $\alpha$ ) $M O D Y 3 / T C F 1)$ on chromosome $12 \mathrm{q}$, insulin promoter factor-1 (IPF1/MODY4) on chromosome 13q and hepatocyte nuclear factor-1 beta (HNF-1 $/ M O D Y 5 /$ $T C F 2$ ) on chromosome 17cen-q. We have screened the $H N F-4 \alpha, H N F-1 \alpha$ and $H N F-1 \beta$ genes in members of 18 MODY kindreds who tested negative for glucokinase mutations. Five missense (G31D, R159W,
A161T, R200W, R271W), one substitution at the splice donor site of intron 5 (IVS5nt $+2 \mathrm{~T} \rightarrow \mathrm{A}$ ) and one deletion mutation (P379fsdelT) were found in the $H N F-1 \alpha$ gene, but no MODY-associated mutations were found in the $H N F-4 \alpha$ and $H N F-1 \beta$ genes. Of 67 French MODY families that we have now studied, $42(63 \%)$ have mutations in the glucokinase gene, $14(21 \%)$ have mutations in the $H N F-1 \alpha$ gene, and $11(16 \%)$ have no mutations in the $H N F-4 \alpha$, $I P F 1$ and $H N F-1 \beta$ genes. Eleven families do not have mutations in the five known MODY genes suggesting that there is at least one additionnal locus that can cause MODY. [Diabetologia (1998) 41:1017-1023]

Keywords Genetics, MODY, glucokinase gene, HNF$1 \alpha, \mathrm{HNF}-4 \alpha, \mathrm{HNF}-1 \beta, \mathrm{IPF} 1$, transcription factors
Maturity-onset diabetes of the young (MODY) is a subtype of Type II (non-insulin dependent) diabetes mellitus characterised by early onset, usually before

Received: 5 January 1998 and in revised form: 8 April 1998

Corresponding author: P. Froguel, CNRS EP 10, Institut Pasteur de Lille, 1 rue du Professeur Calmette, BP 245, 59019 Lille, France

Abbreviations: MODY, Maturity-onset diabetes of the young; GCK, glucokinase gene; HNF-1 $\alpha$, Hepatocyte Nuclear Factor-1 alpha; HNF-4 $\alpha$, Hepatocyte Nuclear Factor-4 alpha; HNF-1 $\beta$, Hepatocyte Nuclear Factor-1 beta; IPF1, Insulin Promoter Factor-1; OGTT, oral glucose tolerance test; IGT, impaired glucose tolerance; SSCP, single strand conformation polymorphism; MFH, mild fasting hyperglycaemia; ANOVA, analysis of variance; Lod-score, logarithm of odds score (logarithm of the ratio of the likelihood of our data under assumption of linkage on the likelihood of our data under the assumption of no linkage.
25 years of age, an autosomal dominant mode of inheritance with high penetrance, and a primary defect of insulin secretion [1,2]. MODY is not an uncommon disorder and could account for about 2 to $5 \%$ of all cases of Type II diabetes [3]. MODY is genetically heterogeneous and to date five MODY genes have been identified on chromosomes 20q12-q13.1 (MODY1) [4, 5], 7p15-p13 (MODY2) [6, 7], 12q24.2 (MODY3) [8, 9], 13q12.1 (MODY4) [10, 11] and 17cen-q21.3 (MODY5) [12]. The MODY2 gene encodes the glycolytic enzyme glucokinase which plays a major role in the regulation and integration of glucose metabolism in pancreatic beta cells and liver [13]. Recent studies have shown that mutations in three transcription factors, hepatocyte nuclear factor-4 $\alpha(H N F-4 \alpha)$ [5] (gene symbol TCF14), hepatocyte nuclear factor-1 $\alpha(H N F-1 \alpha)[9,14](T C F 1)$ and insulin promoter factor-1 (IPF1) [10], are responsible for the MODY1, MODY3 and MODY4 subtypes, re- 
spectively. HNF- $4 \alpha$ is a member of the steroid/thyroid-hormone receptor superfamily [15] and an upstream regulator of $H N F-1 \alpha$ expression [16]. The genes encoding these two transcription factors are expressed in a number of tissues including pancreatic islets of Langerhans [17]. IPF1 is an homeo-domain transcription factor which is a key regulator of insulin and somatostatin genes expression. IPF1 appears to serve also as a master control factor of pancreatic development [11]. More recently, Horikawa Y. et al. [12] described a nonsense mutation, R177X, of the $H N F-1 \beta$ gene in a MODY associated family with bilineal inheritance of diabetes. HNF- $1 \beta$ is a homeodomain transcription factor which functions as a homodimer or a heterodimer with HNF-1 $\alpha$. Horikawa Y. et al. have screened the $H N F-1 \beta$ gene in 57 unrelated Japanese subjects with MODY. They found only one family with a mutation $(2 \%)$.

The relative prevalence of the different MODY subtypes remains uncertain. We have suggested previously that glucokinase mutations were responsible for about $50 \%$ of MODY cases in France [7]. Subsequently, we observed that in half of the non glucokinase-linked MODY families that we studied, diabetes was linked to markers on chromosome $12 \mathrm{q}$, which suggested that the relative prevalence of MODY3 was at least $25 \%$ [8]. These results were confirmed by the identification of nine different HNF-1 $\alpha$ mutations in ten MODY3-linked kindreds [14]. On the other hand, we had reported that only two families in our study were marginally linked to the MODY1 locus [6], which suggests that MODY1 is less common in our subjects than the other subtypes of MODY.

As $25 \%$ of the French MODY families we studied have so far shown no evidence for linkage with any of the three known MODY loci, we proposed that there is at least one additional MODY locus [8]. The recent identification of the MODY1 and $M O D Y 3$ genes allowed us to re-examine the evidence for the existence of this putative MODYx locus by directly screening for mutations in the known genes in these families. The aim of the present study was to analyse the MODY1 and MODY3 status of 18 non-glucokinase MODY families, by direct mutation screening of the $H N F-1 \alpha$ and $H N F-4 \alpha$ genes, given that we excluded mutations in IPFI as a cause of MODY in these families [18]. Finally, given the recent finding regarding the role of TCF2 gene in MODY, we also screened this gene for mutations in the 11 families with no mutations in the four other known MODY genes.

\section{Subjects and methods}

Subjects and kindreds. Probands of 18 families were studied, 16 of which were of French (F30, F253, F387, F538, F571, F624, F662, F681, F693, F694, F706, F709, F725, F728, F743, F748), one of Belgian (MT), and one of Brazilian (VA) ancestry. These subjects were seen by one of us at the outpatient clinics, or referred to us by their physician with a clinical diagnosis of MODY, including onset before 25 years of age and familial Type II diabetes consistent with an autosomal dominant inheritance. Clinical data were obtained for each available member $(n=213)$ of the 18 families during the course of a standard clinical examination performed either by one of us or the subject's personal physician. Subjects who were not overtly diabetic underwent oral glucose tolerance testing (OGTT) and a diagnosis of diabetes or impaired glucose tolerance (IGT) was made according to the criteria of the World Health Organisation [19]; diabetes, fasting plasma glucose of $7.8 \mathrm{mmol} / \mathrm{l}$ or more or 2 -h post oral glucose load of $11.1 \mathrm{mmol} / \mathrm{l}$ or more; and IGT, $2 \mathrm{~h}$-post oral glucose load of $7.8 \mathrm{mmol} / \mathrm{l}$ or more. Subjects were considered to have mild fasting hyperglycaemia (MFH) if they had a fasting plasma glucose level between 6.1 and $7.7 \mathrm{mmol} / \mathrm{l}$ on two separate occasions. Out of the $213 \mathrm{fam}-$ ily members, 107 (50.2\%) were men and 106 (49.8\%) were women; 65 (30\%) of them had diabetes, 14 (7\%) had IGT, 12 (6\%) had MFH, and 122 (57\%) were normoglycaemic. Average age at the time of the study ( \pm SD) was $36 \pm 18$ years and average BMI was $22.7 \pm 4.4 \mathrm{~kg} / \mathrm{m}^{2}(23.5 \pm 4.5$ and $22.0 \pm 4.2$ $\mathrm{kg} / \mathrm{m}^{2}$ for subjects with hyperglycaemia and normoglycaemia, respectively). Average age of diagnosis of hyperglycaemia was $30 \pm 17$ years (range 3-79). In all but one kindred (F538), hyperglycaemia was present in three consecutive generations and in all kindreds at least two subjects were diagnosed with Type II diabetes before or at the age of 25 years. All these families tested negative for glucokinase mutations by single strand conformation polymorphishm (SSCP) screening.

HNF-4 $\alpha$ gene (MODY1) screening. Genomic DNA was extracted from whole-blood samples using the Puregene kit (Gentra, Minneapolis, Minn., USA). The promoter region and the 11 exons and flanking intronic regions of the $H N F-4 \alpha$ gene of the 18 probands were amplified by polymerase chain reaction using the sequence specific primers described previously [5]. Polymerase chain reaction was performed in a $50 \mu \mathrm{l}$ volume containing $100 \mathrm{ng}$ of genomic DNA, $0.25 \mathrm{mmol} / \mathrm{l}$ of each primer and $1.5 \mathrm{U}$ of AmpliTaqGold. All primers and Taq for this study were purchased from Perkin-Elmer Applied Biosystems (Foster City, Calif., USA). Polymerase chain reaction cycling conditions were denaturation at $94{ }^{\circ} \mathrm{C}$ for $12 \mathrm{~min}$ followed by 30 cycles of denaturation at $94^{\circ} \mathrm{C}$ for $30 \mathrm{~s}$, annealing at $62^{\circ} \mathrm{C}$ for $30 \mathrm{~s}$ and extension at $72^{\circ} \mathrm{C}$ for $45 \mathrm{~s}$, with a final extension at $72^{\circ} \mathrm{C}$ for $10 \mathrm{~min}$ for all primers except for those of exon $1 \mathrm{~A}$ and 6 , where annealing was at $60^{\circ} \mathrm{C}$ for $30 \mathrm{~s}$ and extension at $72^{\circ} \mathrm{C}$ for $30 \mathrm{~s}$. Polymerase chain reaction products were purified using P60 columns (Bio-Rad, Richmond, Calif., USA) before both strands were sequenced using a Dye Terminator Cycle Sequencing Ready Reaction kit with AmpliTaq DNA Polymerase FS and an ABI Prism 377 sequencer (Perkin-Elmer Applied Biosystems).

$H N F-1 \alpha$ gene (MODY3) screening. The HNF-1 $\alpha$ gene was screened for mutations by direct sequencing for 13 of the probands or by an automated fluorescent SSCP technique, followed by sequencing of the SSCP variants for the remaining 5 probands. Whenever a mutation or SSCP variant was found in a proband, available family members were screened for its presence. The method used for screening the $H N F-1 \alpha$ gene was adapted from a new SSCP protocol that we have developed, based on fluorescent end-labelling with an automated sequencer, using primers extended by universal M13 sequences [20]. The primers for the promoter region and the ten exons and flanking intronic regions of the HNF-1 $\alpha$ gene and the 
Table 1. Sequences of polymerase chain reaction primers used for amplification of human $H N F-1 \beta$ gene

\begin{tabular}{llll}
\hline Region & Forward primer $\left(5^{\prime}-3^{\prime}\right)$ & Reverse primer $\left(5^{\prime}-3^{\prime}\right)$ & Product size $(\mathrm{bp})$ \\
\hline Promoter & CATGAACCCCGAAGAGTGGTG & GCCTCCAGACACCTGTTACT & 423 \\
Exon $1-1$ & GGCGATCATGGCAAGTTAGAAG & TTGGTGAGAGTATGGAAGACC & 392 \\
Exon $1-2$ & GGGGTTTCTTGTGAAACTCC & TTGGTGGGAAACGGGCTTGG & 536 \\
Exon 2 & CTCCCACTAGTACCCTAACC & GAGAGGGCAAAGGTCACTTCAG & 291 \\
Exon 3 & AGTGAAGGCTACAGACCCTATC & TTCCTGGGTCTGTGTACTTGC & 365 \\
Exon $4-1$ & TGTGTTTGGGCCAAGCACCA & AACCAGATAAGATCCGTGGC & 381 \\
Exon $4-2$ & AACCAGACTCACAGCCTGAACC & TCACAGGGCAATGGCTGAAC & 293 \\
Exon 5 & TGCCGAGTCATTGTTCCAGG & CCTCTTATCTTATCAGCTCCAG & 276 \\
Exon 6 & CTGCTCTTTGTGGTCCAAGTCC & GAGTTTGAAGGAGACCTACAG & 288 \\
Exon 7 & ATCCACCTCTCCTTATTCCAG & ACTTCCGAGAAAGTTCAGACC & 340 \\
Exon 8 & TTTGCCTGTGTATGCACCTTG & GCCGAGTCCATGCTTGCCAC & 257 \\
Exon 9 & CTTTGCTGGTTGAGTTGGGC & TTCCATGACAGCTGCCCAGAG & 208 \\
\hline
\end{tabular}

Table 2. HNF-1 $\alpha$ gene mutations in MODY3 kindreds

\begin{tabular}{|c|c|c|c|c|c|}
\hline \multirow[t]{2}{*}{ Kindred } & \multicolumn{2}{|c|}{ Location of mutation } & \multirow[t]{2}{*}{ Nucleotide change } & \multirow[t]{2}{*}{ Amino-acid change } & \multirow[t]{2}{*}{ Designation } \\
\hline & Exon & Codon & & & \\
\hline F709 & 1 & 31 & $\mathrm{GGT} \rightarrow \mathrm{GAT}$ & Gly $\rightarrow$ Asp & G31D (b) \\
\hline MT & 2 & 159 & $\mathrm{CGG} \rightarrow \mathrm{TGG}$ & Arg $\rightarrow$ Trp & R159W (a) \\
\hline F681 & 2 & 161 & $\mathrm{GCC} \rightarrow \mathrm{ACC}$ & $\mathrm{Ala} \rightarrow \mathrm{Thr}$ & A161T (b) \\
\hline VA & 3 & 200 & $\mathrm{CGG} \rightarrow \mathrm{TGG}$ & $\operatorname{Arg} \rightarrow \operatorname{Trp}$ & R200W (a) \\
\hline F693 & 4 & 271 & $\mathrm{CGG} \rightarrow \mathrm{TGG}$ & $\operatorname{Arg} \rightarrow \operatorname{Trp}$ & R271W (a) \\
\hline F706 & Intron 5 & nt 2 & $\begin{array}{l}\mathrm{T} \rightarrow \mathrm{A} \\
\text { at splice donor site }\end{array}$ & & IVS5nt $+2 \mathrm{~T} \rightarrow \mathrm{A}(\mathrm{a})$ \\
\hline F387 & 6 & 379 & Deletion of $\mathrm{T}$ & Frameshift & P379fsdelT (b) \\
\hline
\end{tabular}

MT, Belgian ancestry; VA Brazilian ancestry

(a) mutation detected by automated fluorescent SSCP

(b) mutation detected by direct sequencing

PCR conditions used for direct sequencing and for the SSCP screening and subsequent sequencing of the positive fragments can be obtained from the authors (Diabetes Website). All probands with no mutations detected by SSCP where screened by direct sequencing using universal M13 primers.

IPF1 gene (MODY4) screening. The two exons, proximal promoter region and $-180 \mathrm{~kb}$ enhancer of the IPF1 gene have been sequenced on both strands in the 11 MODY families with no mutations in the other MODY genes as described elsewhere [18].

$H N F-1 \beta$ gene (MODY5) screening. The nine exons, flanking introns and minimal promoter region of the TCF2 gene have been sequenced on both strand using universal M13 primers as described above in the eleven MODY families with unknown aetiology. The primer sequences were kindly communicated by Dr G.I. Bell ([12] personnal communication, Table 1).

Polymorphic markers genotyping and Logarithm of odds scores (Lod-scores) calculation. Out of the 18 kindreds 4 (F30, F253, F387, F538) have been tested previously for linkage with markers on MODY1 and MODY3 loci [6, 8, 21]. None of them showed significant evidence for linkage with these loci. We typed 9 of the 11 negative families (F30, F253, F538, F571, F624, F694, F725, F743, F748) $(n=118)$ with fluorescently labelled polymorphic markers localised near the MODY1 (ADA), MODY2 (GCK-CA), MODY3 (D12S1349, D12S395), MODY5 (D17S1788) loci respectively. The samples were loaded on an ABI377 sequencer (Perkin-Elmer Applied Biosystems) and analysed using the GeneScan 2.1 and Genotyper 2.0 softwares (Perkin-Elmer Applied Biosystems). The Lod-scores has been computed as usual [8].

Clinical and biological data analysis. Results are expressed as means \pm SD unless otherwise stated. Quantitative traits were compared by analysis of variance (ANOVA). When ANOVA was significant, comparisons between pairs were made using Tukey-Kramer HSD test [22]. Qualitative traits were analysed by contingency table chi-square tests. Statistics were calculated with the JMP software (SAS Institute, Cary, N. C., USA).

\section{Results}

$H N F-4 \alpha$ gene (MODY1) screening. No mutations were observed in the promoter region or in the $11 \mathrm{ex}-$ ons and flanking intronic regions of the $H N F-4 \alpha$ gene in any of the 18 probands among the 18 MODY families. In F.30, we found the T/I130 variant (exon4) described previously as a polymorphism [5]. The Ile allele does not co-segregate with diabetes in this family (Fig. 1).

HNF-1 $\alpha$ gene (MODY3) screening. The screening of a proband from a family (F387) that previously 

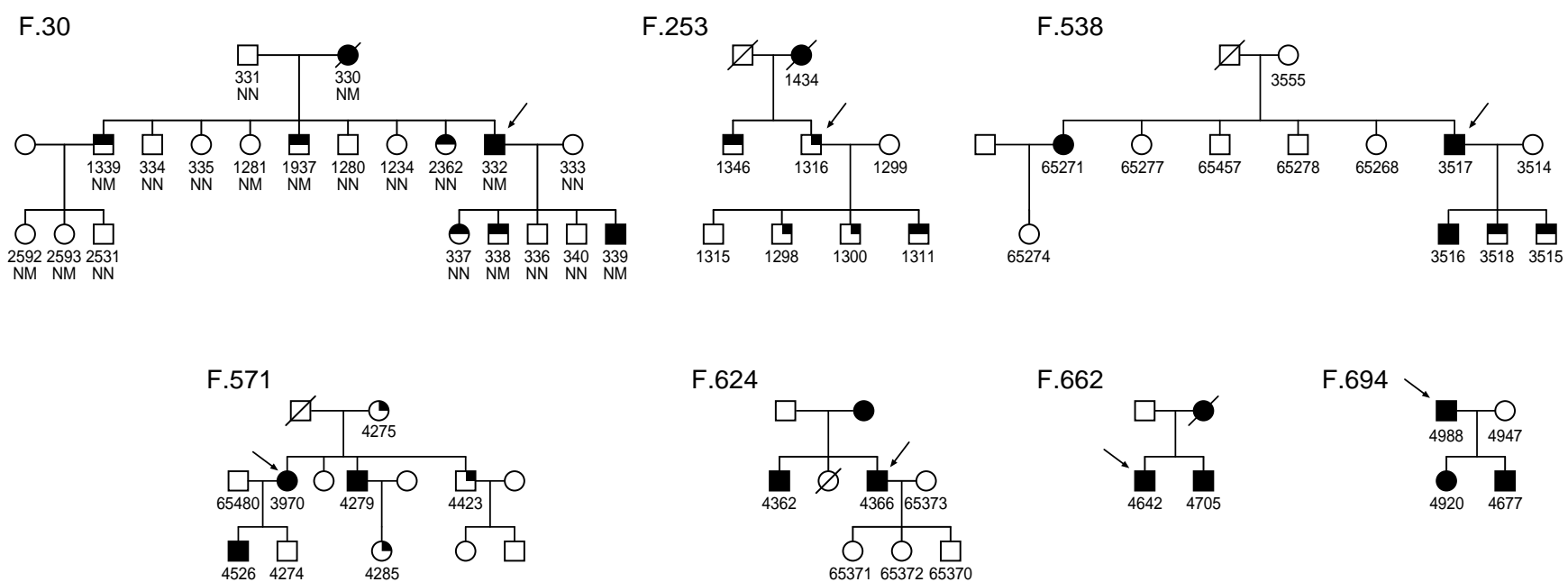

F.624

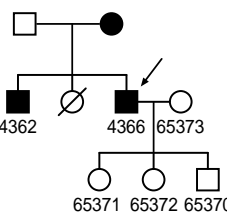

F.728

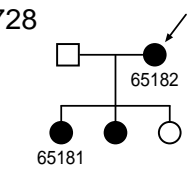

F.662
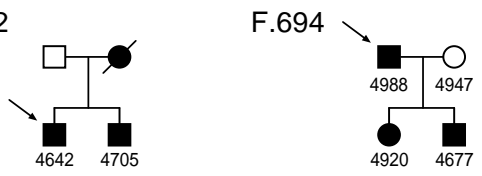

F.748

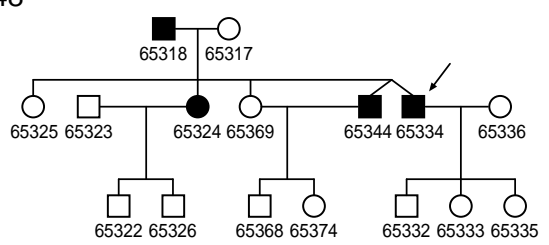

F.725

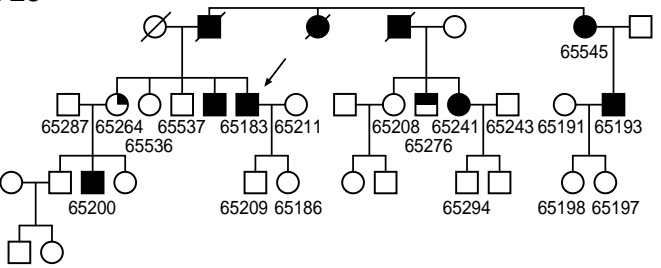

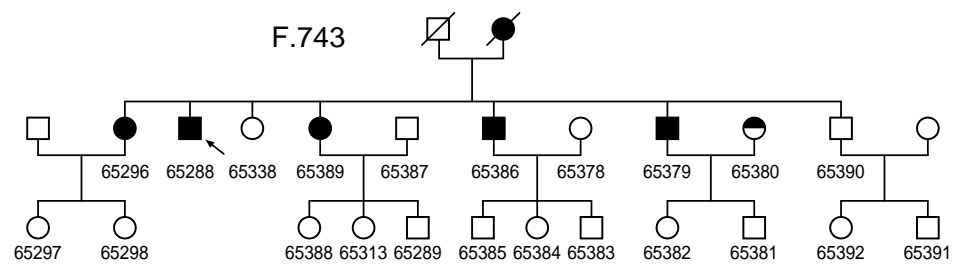

Fig. 1. Pedigrees of 11 French MODY families with no mutations in the 5 known MODY genes. The numbers under the symbols are identification numbers of individuals from whom DNA was available. Squares denote male and circle female family members. An arrow indicates the individual from each pedigree who was screened for mutations. The segregation of the T/I130 polymorphism of the $H N F-4 \alpha$ gene found in F.30 is shown: $\mathrm{N}$, normal; $\mathrm{M}$, mutant

showed exclusion of linkage with markers near the MODY3 locus [8] showed a deletion that removed the T of codon 379 (exon 6) resulting in a frameshift. We observed five missense mutations and one substitution in splice donor site of intron 5 in six probands (Table 2, Fig. 2). Each of the variants co-segregated with MODY in these seven kindreds, suggesting that they play a causal role in the development of diabetes. All patients were heterozygous for these mutations. All mutations are located in sites likely to be important for HNF-1 $\alpha$ function. The R200W and R271W mutations are localised in the DNA recognition domain (homeodomain) of the DNA binding region. The R159W and A161T mutations are localised in the B-domain of the DNA binding region and the
P379fsdelT deletion is localised in the transactivation domain of HNF-1 $\alpha$. Three of these mutations were detected by the automated fluorescent SSCP technique, and the remaining four mutations were detected by direct sequencing (Table 2).

IPF1 gene screening (MODY4). As presented elsewhere [18], we found no mutations either in the coding and splicing sites sequence or in the proximal promoter and $-180 \mathrm{~kb}$ putative enhancer region in any of the 11 probands among the 11 MODY families which tested negative for mutations screening in MODY1, 2 , and 3 genes.

HNF-1 $\beta$ gene screening (MODY5). No mutations were found in the nine exons, flanking introns and minimal promoter region of the TCF2 gene among those same 11 families (data not shown).

Polymorphic markers genotyping and Lod-scores calculation. All the cumulative Lod-scores showed exclusion of linkage of diabetes with the MODY1, $M O D Y 2, M O D Y 3$, and MODY5 loci in 9 of the 11 MODY families. Moreover, none of the Lod-scores indicated evidence of linkage in any of the MODY 
Table 3. Demographic, clinical and biological profile of MODY subtypes (d)

\begin{tabular}{|c|c|c|c|c|}
\hline & MODY-2 & MODY-3 & Other MODY & $p$ \\
\hline Kindreds $(n)$ & 45 & 16 & 11 & \\
\hline $\begin{array}{l}\text { Glucose tolerance status: MFH-IGT/diabetes } \\
(n \text { and } \%)\end{array}$ & $\begin{array}{l}162 / 135 \\
(55 \% / 45 \%)\end{array}$ & $\begin{array}{l}26 / 83 \\
(24 \% / 76 \%)\end{array}$ & $\begin{array}{l}20 / 32 \\
(38 \% / 62 \%)\end{array}$ & 0.0001 \\
\hline Men/women & $149 / 148$ & $49 / 60$ & $36 / 16$ & 0.02 \\
\hline Age (years) & $36 \pm 21$ & $39 \pm 19$ & $44 \pm 18(\mathrm{~b})$ & 0.02 \\
\hline $\mathrm{BMI}(\mathrm{Kg} / \mathrm{m} 2)$ & $22.1 \pm 4.1$ & $22.4 \pm 3.0$ & $24.5 \pm 5.0(\mathrm{~b})(\mathrm{c})$ & 0.003 \\
\hline $\begin{array}{l}\text { Age at Diagnosis (years): } \\
\text { All subjects } \\
\text { Minimal age in the kindreds } \\
\text { Duration of Hyperglycaemia (years) }\end{array}$ & $\begin{aligned} 25 & \pm 17 \\
7 & \pm 6 \\
11 & \pm 10(\mathrm{c})\end{aligned}$ & $\begin{array}{l}23 \pm 12 \\
13 \pm 4 \\
20 \pm 14\end{array}$ & $\begin{array}{l}33 \pm 19(b)(c) \\
16 \pm 9(b) \\
12 \pm 11(c)\end{array}$ & $\begin{array}{l}0.002 \\
0.001 \\
0.0001\end{array}$ \\
\hline Fasting Glucose (mmol/l) & $7.0 \pm 1.1$ & $7.7 \pm 3.4(\mathrm{~b})$ & $\mathrm{h} 7.8 \pm 2.7$ & $0.0001(\mathrm{a})$ \\
\hline Fasting Insulin (pmol/l) & $59 \pm 41$ & $39 \pm 31(b)$ & $36 \pm 29(b)$ & $0.0001(\mathrm{a})$ \\
\hline $2 \mathrm{~h}$ Glucose $(\mathrm{mmol} / \mathrm{l})$ & $9.2 \pm 2.9(\mathrm{c})$ & $12.7 \pm 6.1$ & $9.5 \pm 4.4(\mathrm{c})$ & 0.0001 (a) \\
\hline $2 \mathrm{~h}$ Insulin (pmol/l) & $182 \pm 150$ & $120 \pm 102(b)$ & $172 \pm 189$ & $0.0008(\mathrm{a})$ \\
\hline $2 \mathrm{~h}$ Insulin/Glucose (pmol/mmol) & $20.2 \pm 13.0$ & $11.0 \pm 12.6(b)$ & $21.7 \pm 25.5$ & $0.0001(\mathrm{a})$ \\
\hline Treatment: Diet/OHA/Insulin ( $n$ and \%) & $\begin{array}{l}204 / 53 / 6 \\
(78 \% / 20 \% / 2 \%)\end{array}$ & $\begin{array}{l}26 / 43 / 14 \\
(31 \% / 52 \% / 17 \%)\end{array}$ & $\begin{array}{l}25 / 14 / 4 \\
(58 \% / 33 \% / 9 \%)\end{array}$ & 0.0001 \\
\hline
\end{tabular}

Date expressed as means \pm SD. $2 \mathrm{~h}$ glucose and insulin are values following an oral glucose tolerance test.

Statistics are contingency-table chi-square test (qualitative traits) and ANOVA (quantitative traits).

(b) represent statistically significant differences $(p<0.05)$ as compared with MODY-2, and (c) as compared with MODY-3 (Tukey-Kramer HSD test following ANOVA).

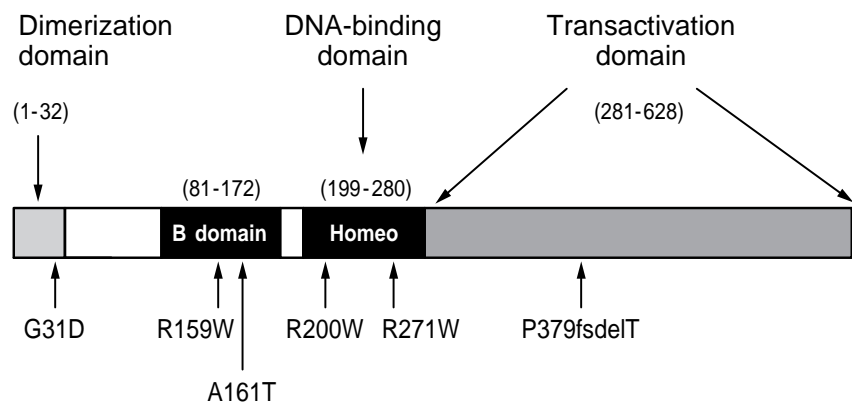

Fig. 2. Schematic representation of HNF-1 $\alpha$ protein structure. The different functional domains are represented by the hatched boxes. Amino-acid residue numbers are indicated in parenthesis. The relative position of the six mutations found in coding sequence among MODY3 families are shown

families (data not shown). The MODY4 locus have been also excluded [18].

Clinical profile of MODY kindreds. Out of the 18 kindreds 11 carry no mutations in any of the 5 known MODY loci (Fig. 1). Table 3 shows the clinical and biological data of affected individuals from these families (other-MODY) as compared with data from subjects from 45 MODY2 ([23] and unpublished results) and 16 MODY3 ([14] and this report) kindreds. The prevalence of overt diabetes in the subjects with other-MODY (62\%) seems to be intermediate between (a) comparisons adjusted by duration of hyperglycaemia MFH: mild fasting hyperglycaemia (see methods for definition); IGT: impaired glucose tolerance; OHA: oral hypoglycaemic agents

(d) Those statistics include three MODY2 and two MODY3 families which are not of French ancestry as cited in the text; data partially reported in references 8,23 and 24

the low prevalence in MODY2 (45\%) and high prevalence in MODY3 (76\%) subjects. Insulin secretion assessed by the 2-h insulin to glucose ratio during an OGTT, was significantly decreased in MODY3 subjects as compared with MODY2 subjects suggesting the presence of a more severe glucose-stimulated insulin secretory defect. Subjects with other-MODY presented heterogeneous responses. The age of diagnosis of diabetes was significantly higher in otherMODY subjects than in the other groups. To avoid the ascertainment bias associated with this parameter we also compared the minimal age of diagnosis in the kindreds, which was significantly lower in MODY2 than in MODY3 and other-MODY kindreds. These clinical and biological data have, in part, been reported previously $[8,23,24]$.

\section{Discussion}

The screening for mutations of the $H N F-1 \alpha / M O D Y 3$ gene in 18 non-glucokinase MODY families led to the identification of five missense mutations, one substitution in a splice donor site and one deletion of a base-pair in the coding region. The R159W and the P379fsdelT had been observed already in a British MODY kindred and a Danish MODY family, respectively $[25,26]$ but five of these mutations have not been described previously. These seven mutations 
seem to have a causative role in the development of diabetes. All of them co-segregate with the MODY phenotype in the kindreds and are located in sites likely to play an important role in HNF-1 $\alpha$ function. Three of the four missense mutations were C-to-T transitions occurring at $\mathrm{CpG}$ dinucleotides, as observed already in many other HNF- $1 \alpha$ mutations $[9$, $14,25,27]$. These are known to be a hot spot for nucleotide substitutions in mammalian genes, presumably due to the deamination of methylated cytosine to thymidine [28]. The deletion of a base-pair in codon 379 results in a frameshift with the generation of a stop codon resulting in a predicted protein of 382 amino-acids. Two different types of deletion mutations have now been observed at codon 379: deletion of T in two families, one of French and one of Danish ancestry [26] and a deletion of CT in two British MODY families $[9,25]$. These proteins are probably devoid of transcriptional activity. Truncated HNF-1 $\alpha$ proteins of 348 to 416 amino acids in length have been found to accumulate outside the nuclear membrane, unable to activate target genes [29]. The effects of the amino-acid changes of the missense mutations on HNF-1 $\alpha$ function remain to be investigated. The P379fsdelT mutation was found in a family (F387) where the MODY3 locus had been excluded by linkage analysis with the marker D12S76 (Lodscore $=-2.24)$ [8]. Retrospective examination of this family showed that one subject, considered to be affected, did not carry the mutation co-segregating with MODY in the family. This subject who had impaired glucose tolerance four years ago, now presents with normal glucose tolerance. Linkage analysis reassed in the family and taking into account this change in phenotype yields a Lod-score of 0.1 at $0 \mathrm{cM}$ for the same marker. This observation points out the importance of prospective phenotyping in genetic studies of Type II diabetes, especially for subjects showing mild hyperglycaemia at the initial testing.

Our results indicate that mutations in the $H N F-4 \alpha$ / MODY1 gene are not a frequent cause of MODY in subjects of French ancestry. We failed to detected any mutation in the promoter or in the 11 exons and flanking intronic regions of the HNF- $4 \alpha$ gene in the families we studied. Although we found the T/I130 variation in family 30 , it did not co-segregate with diabetes in this family.

Out of the 18 kindreds we studied, 11 have no mutations in the 5 known MODY genes. This result is consistent with linkage studies which suggested the existence of at least one additional locus responsible for the MODY phenotype $[8,30]$. As undiscovered mutations could still exist, particularly in unscreened regulatory regions, we typed nine families (out of 11) usable for linkage analyses with polymorphic markers mapping near $M O D Y 1, M O D Y 2, M O D Y 3$, $M O D Y 4$ and MODY5 loci. The Lod-scores did not give evidence of linkage of these loci with the
MODY phenotype in those families. Analyses of a set of 67 MODY families of French ancestry that we collected show that $42(63 \%)$ ([23] and unpublished results) are MODY2 and 14 (21\%) ([14] and this report) are MODY3 subtypes, while none is MODY1, $M O D Y 4$ or MODY5 subtypes. Thus, the additional unknown MODY locus or loci represent $16 \%$ of the families we studied. For these computations of prevalences, we have excluded from our panel the MODY families collected in Belgium $(n=1)$ (this report), Brazil $(n=3)$ ([23] and this report), and the Congo $(n=1)$ [23]. In contrast to our results, Hattersley et al. [25] have observed that glucokinase/ MODY2 mutations represented only $11 \%$ of cases of MODY in a group of British kindreds but HNF$1 \alpha$ mutations were highly prevalent $(73 \%)$ in that group. These contrasting results could be due to differences in the genetic background of the two populations, or could reflect, at least in part, an ascertainment bias in the recruitment of families. Indeed, hyperglycaemia of MODY2 often starts in childhood, while MODY3 is most often diagnosed after puberty or in early adult life. Many of the families we studied were referred to us by paediatric departments and this might have introduced bias in the relative proportion of the different MODY subtypes.

In conclusion, we have screened the $H N F-4 \alpha /$ $M O D Y 1$ and $H N F-1 \alpha / M O D Y 3$ genes for mutations in 18 kindreds that fulfilled the strict definition of MODY and tested negative for glucokinase mutations. We found seven mutations in the $H N F-1 \alpha$ gene and none in the $H N F-4 \alpha$ gene. Of the kindreds 11 carried no mutations in the 5 known MODY loci including the IPF1 and $H N F-1 \beta$ genes and did not show evidence of linkage with those loci, implying that additional locus or loci are associated with MODY ([18] and this report). The identification of glucokinase as a diabetes susceptibility gene has led to the reassessment of the physiological and pathophysiological role of this enzyme. The recent identification of MODY1, MODY3, MODY4 and MODY5 genes now opens entirely new perspectives in the understanding of the molecular basis of Type II diabetes. Identification of the remaining MODY gene(s) will contribute to our knowledge of the mechanisms of glucose homeostasis and its disorders. Furthermore it will enable a molecular diagnosis to be made of all MODY patients.

Acknowledgements. We thank the patients and their families for their co-operation. This work was supported by the French Ministry of Research, Pasteur Institut, Centre National de la Recherche Scientifique, the European Union (Biomed 2 grant no. BMH4-CT95-0662 grants), Glaxo-Welcome, Institut de Recherches Internationales Servier and Institut Lilly France (Contrat de Recherche Lilly-ALFEDIAM). 


\section{References}

1. Fajans SS (1990) Scope and heterogeneous nature of MODY. Diabetes Care 13: 49-64

2. Froguel P, Vaxillaire M, Velho G (1997) Genetic and metabolic heterogeneity of maturity onset diabetes of the young. Diabetes Reviews 5: 123-130

3. Ledermann HM (1995) Is maturity onset diabetes at young age (MODY) more common in Europe than previously assumed? Lancet 345: 648 (Letter)

4. Bell GI, Xiang KS, Newman MV, Wu SH, Wright LG, Fajans SS, Cox NJ (1991) Gene for non-insulin-dependent diabetes mellitus (maturity onset diabetes of the young subtype) is linked to DNA polymorphism on chromosome 20 q. Proc Natl Acad Sci USA 88: 1484-1488

5. Yamagata K, Furuta H, Oda O et al. (1996) Mutations in the hepatocyte nuclear factor 4 alpha gene in maturityonset diabetes of the young (MODY1). Nature 384: 458-460

6. Froguel P, Vaxillaire M, Sun F et al. (1992) Close linkage of glucokinase locus on chromosome $7 \mathrm{p}$ to early onset non-insulin-dependant diabetes mellitus. Nature 356: 162-164

7. Froguel P, Zouali H, Vionnet N et al. (1993) Familial hyperglycaemia due to mutations in glucokinase: definition of a subtype of diabetes mellitus. N Engl J Med 328: 697-702

8. Vaxillaire M, Boccio V, Philippi A et al. (1995) A gene for maturity onset diabetes of the young (MODY) maps to chromosome 12q. Nat Genet 9: 418-423

9. Yamagata K, Oda N, Kaisaki PJ et al. (1996) Mutations in the hepatocyte nuclear factor 1 alpha gene in maturity-onset diabetes of the young (MODY3). Nature 384: 455-458

10. Stoffers DA, Ferrer J, Clarke WF, Habener JF (1997) Early-Onset Type-II Diabetes Mellitus (MODY4) linked to IPF-1. Nat Genet 17: 138-141

11. Stoffers DA, Zinkin NT, Stanojevic V, Clarke WL, Habener JF (1997) Pancreatic agenesis attribuable to a single nucleotide deletion in the human IPF1 gene coding sequence. Nat Genet 15: 106-110

12. Horikawa Y, Iwasaki N, Hara M et al. (1997) Mutation in hepatocyte nuclear factor-1-Beta gene (TCF2) associated with MODY. Nat Genet 17(4):384-385

13. Matschinsky FM (1996) A lesson in metabolic regulation inspired by the glucokinase glucose sensor paradigm. Diabetes 45 : $223-241$

14. Vaxillaire M, Rouard M, Yamagata K et al. (1997) Identification of nine novel mutations in the hepatocyte nuclear factor 1 alpha gene associated with maturity-onset diabetes of the young (MODY3). Hum Mol Genet 6: 583-586

15. Sladek FM, Zhong W, Lai E, Darnell JE (1990) Liver-enriched transcription factor HNF-4 is a novel member of the steroid hormones receptor superfamily. Genes Dev 4: 2353-2365
16. Kuo CJ, Conley PB, Chen L, Sladek FM, Darnell JE, Crabtree GR (1992) A transcriptional hierarchy involved in mammalian cell-type specification. Nature 355: 457-461

17. Tronche F, Yaniv M (1992) HNF1, a homeoprotein member of the hepatic transcription regulatory network. Bioessays 14: 579-587

18. Chèvre JC, Hani EH, Stoffers DA, Habener JF, Froguel $P$ (1998) Insulin Promoter Factor-1 gene (IPF1) is not a major cause of MODY in French caucasians. Diabetes 47: 843-844

19. World Health Organisation Study Group on Diabetes Mellitus Report. (1985) Technical Report Series WHO No. 727. Geneva

20. Boutin P, Hani EH, Vasseur F et al. (1997) Automated fluorescent screening for mutation by SSCP: use of universal M13 dye primers for labelling and detection. Biotechniques 23: $358-362$

21. Vaxillaire M, Vionnet N, Vigouroux C et al. (1994) Search for a third susceptibility gene for maturity onset diabetes of the young: studies with eleven candidate genes. Diabetes 43: 389-395

22. Kramer CY (1956) Extension of multiple range tests to group means with unequal number of replications. Biometrics 12: 309-310

23. Velho G, Blanché H, Vaxillaire M et al. (1997) Identification of 14 new glucokinase mutations and description of the clinical profile of 42 MODY-2 families. Diabetologia 40: $217-224$

24. Velho G, Vaxillaire M, Boccio V, Charpentier G, Froguel P (1996) Diabetes complications in NIDDM kindreds linked to the MODY-3 locus on chromosome 12q. Diabetes Care 19: 915-919

25. Frayling TM, Bulman MP, Ellard S et al. (1997) Mutations in the hepatocyte nuclear factor-1 alpha gene are a common cause of maturity-onset diabetes of the young in the U.K. Diabetes 46: 720-725

26. Hansen T, Eiberg H, Rouard M et al. (1997) Novel MODY3 mutations in the hepatocyte nuclear factor-1a gene. Diabetes 46: 726-730

27. Kaisaki PJ, Menzel S, Lindner T et al. (1997) Mutations in the hepatocyte nuclear factor-1 alpha gene in MODY and early-onset NIDDM: evidence for a mutational hotspot in exon 4. Diabetes 46: 528-535

28. Cooper DN, Krawczak M, Antonarakis SE (1995) The nature and mechanisms of human gene mutations. In: Scriver CR, Sly WS, Beaudet AL et al. The metabolic and molecular basis of inherited disease. McGraw-Hill, (eds) New York, pp 259-291

29. Sourdive DJD (1993) The HNF1 C-terminal domain contributes to transcriptional activity and modulates nuclear localisation. CR. Acad Sci 316: 385-394

30. Dronsfield MJ, Tack CJJ, Bain SC, Hattersley AT (1995) Linkage of the gene for maturity-onset diabetes of the young with markers on the long arm of chromosome $12 \mathrm{q}$. Diabetologia 38 [Suppl 1]:A60 (Abstract) 